\title{
Gastrointestinal haemorrhage from leiomyomata of the small bowel
}

\author{
J. PANG \\ M.A., M.B., M.R.C.P.
}

J. JESSOP

M.B., F.R.C.S.

Whittington Hospital, Highgate Hill, London, N.19

\section{Summary}

Three cases of haemorrhage from small bowel leiomyomata are reported. The features and management of this rare, but important cause of lifethreatening gastrointestinal bleeding, are discussed.

KEY WORDS: small bowel leiomyomata, haemorrhage; gastrointestinal.

\section{Introduction}

Benign tumours are a rare cause of gastrointestinal haemorrhage, being responsible for less than $1 \%$ of cases (Grill and Pichlmaier, 1963). Despite improved diagnostic accuracy in patients presenting with haematemesis and/or melaena with the advent of upper gastrointestinal endoscopy (Dronfield et al., 1982), acute bleeding from a site distal to the duodenum remains a challenging problem. Three cases of bleeding leiomyomata of the small bowel are reported in order to highlight the features and modern management of this rare, but important, cause of massive gastrointestinal haemorrhage.

\section{Case reports}

\section{Case 1}

A 69-year-old spinster had one episode of rectal bleeding and lower abdominal pain in 1970. A barium enema revealed diverticular disease of the pelvic colon.

One year later, she was admitted with a 4-day history of melaena and vomiting, although the vomitus contained no blood. Bleeding continued despite conservative management which included transfusion of 11 units of blood over the next 4 days. At laparotomy, the bleeding source was found to be a tumour in the mid-small intestine, which was resected. It measured $3 \mathrm{~cm}$ in diameter and various pits were observed on the mucosal surface. Some of these communicated with the interior of the tumour, and blood oozed from one of them. The appearances were those of a leiomyoma, subsequently confirmed histo- logically. The postoperative course was uneventfulo and the patient remained well at follow-up.

\section{Case 2}

A 60 -year-old biophysicist was admitted in $198 \dot{6}$ after passing two melaena stools. He had intermitten? dyspepsia for the last 30 years, treated with antacids? Emergency gastroduodenoscopy showed two acute pre-pyloric erosions with no stigmata of recents haemorrhage. Conservative management with ant acids, cimetidine and blood transfusion (total 12 units) was instituted, but he had 3 further melae fifso over the next $24 \mathrm{hr}$. A second upper gastrointestita $\mathrm{\omega}$ endoscopy failed to identify the bleeding source, sq superior mesenteric angiography was performeds This showed a 'blush' in the jejunum consisting of prominent tumour vessels and pooled contrast (Fig 1).

At laparotomy, a small tumour was found in the mid-jejunum, with blood in the lumen distal to the lesion. The tumour was resected, and histologys showed this to be a submucous leiomyoma with foca thinning of the overlying mucosa, and an ulcerate $\delta_{5}$ area containing a medium sized artery with a recen $\underline{B}$. clot. The patient recovered with no complication.

\section{Case 3}

A 39-year-old parts manager had one episode op rectal bleeding in 1980, attributed to haemorrhoids He remained well until February 1982, when he․ passed a large melaena stool and was admitted in shocked state. After initial resuscitation, upper gas trointestinal endoscopy was carried out. This re N vealed no blood in the stomach, but the examination was not entirely satisfactory because the pylorus could not be negotiated. He was managed conservatively, but passed 6 further melaena stools over the next $36 \mathrm{hr}$. A second endoscopy was performed: nợ abnormality was seen in the stomach or duodenum apart from a few small telangiectases of doubtfub significance. A bleeding source distal to the duo 


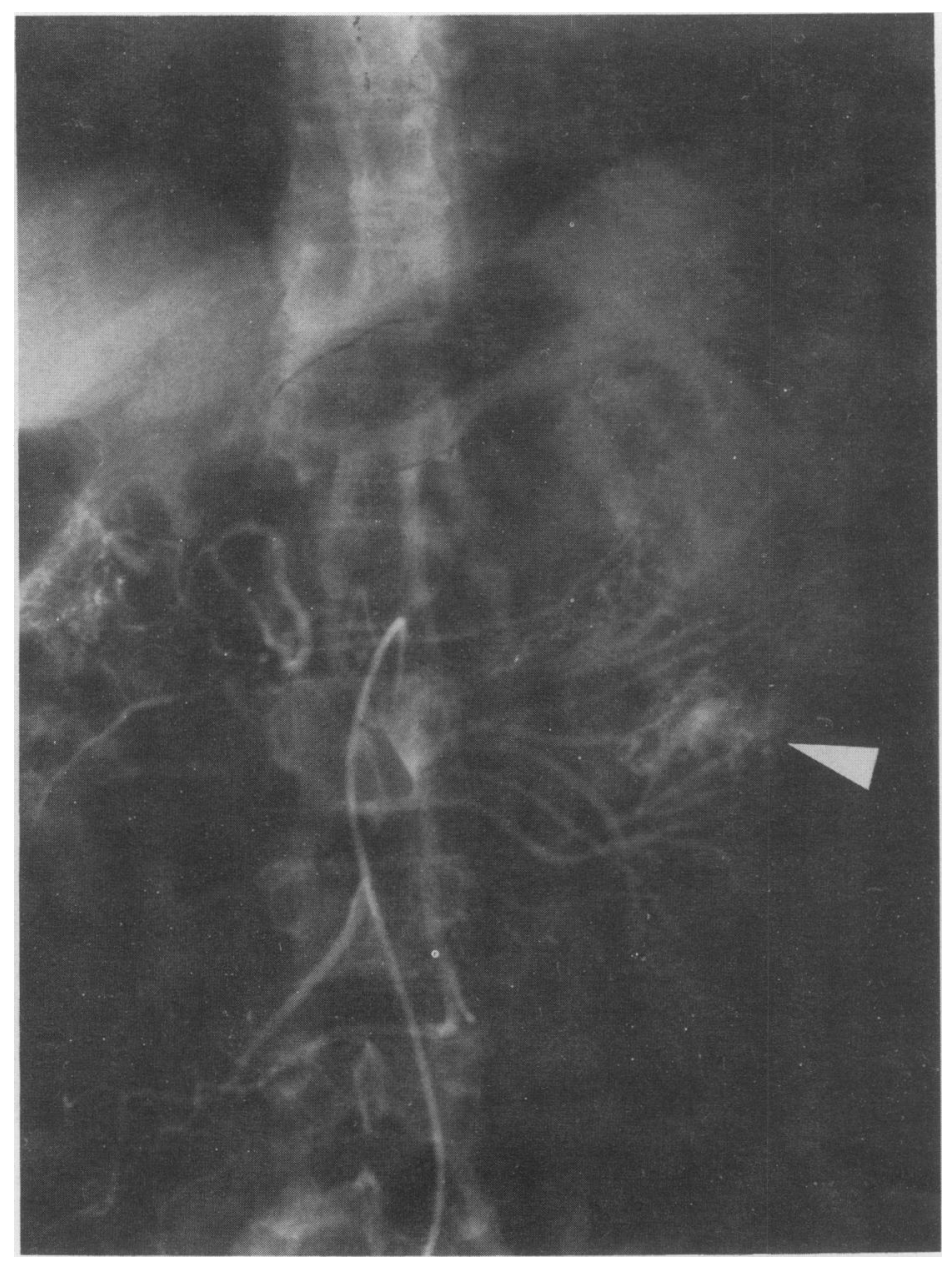

FIG. 1. Superior mesenteric angiogram in Case 2, showing a left sided tumour blush (arrowed) consisting of prominent vessels and pooled contrast.

denum was suspected, and selective visceral angiography was performed on the fourth day after admission. The superior mesenteric angiogram showed a well circumscribed vascular lesion in the jejunum (Fig. 2).

At laparotomy, a firm tumour, $90 \mathrm{~cm}$ from the duodenojejunal junction, was found to be responsible for the bleeding, and it was resected. Opening the specimen revealed a raised, globular tumour, $2 \mathrm{~cm}$ in diameter, with a small central mucosal ulcer. Histology showed this to be a leiomyoma with no malignant changes. The patient received a total of 13 units of blood, (12 preoperatively), and made a full recovery.

\section{Discussion}

Leiomyoma of the small bowel is a rare, benign tumour. It may be asymptomatic, being found far more frequently at autopsy than in surgical specimens (River, Silverstein and Tope, 1956). When symptomatic, the commonest presenting features are abdominal pain, (54\%), haemorrhage $(45 \%)$ and acute obstruction with and without intussusception. Much less common are weight loss and a palpable mass; perforation is extremely rare (Wilson et al., 1975). The peak age of occurrence is the fifth and sixth decades, and both sexes are fairly equally affected.

Haemorrhage is characteristically massive and 


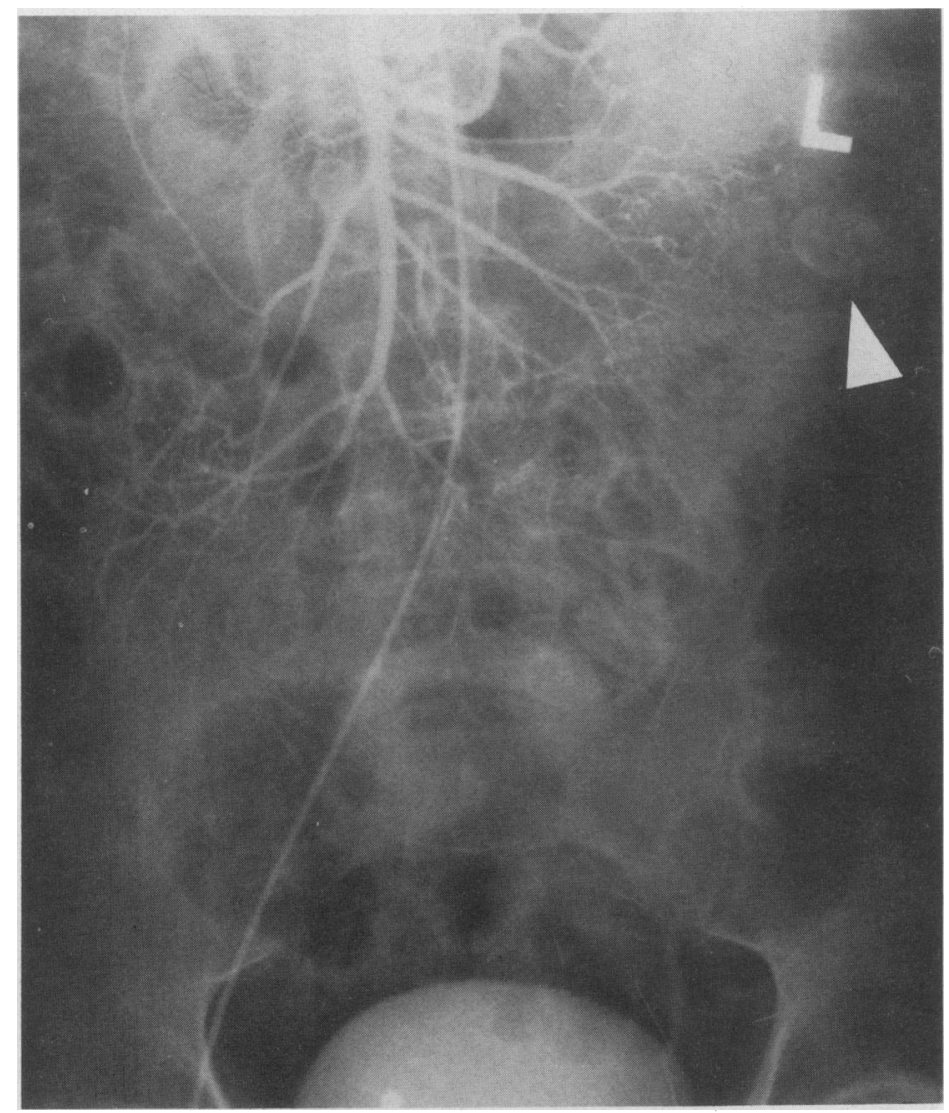

FIG. 2. Superior mesenteric angiogram in case 3, showing a well circumscribed, rounded, hyper-vascular lesion (arrowed).

recurrent, with varying intervals between bleeds. In terms of blood loss, the 3 cases in this series are fairly typical, each requiring over 10 units of blood. Definitive diagnosis is often difficult and multiple hospital admissions are common. Undoubtedly, the distribution of small bowel leiomyoma is an important factor. It occurs mainly in the jejunum (44\%) and ileum $(37 \%)$ with the remainder $(19 \%)$ in the duodenum (Wilson et al., 1975). It is noteworthy that one fifth of these tumours are in the duodenum despite its relatively short length, and might therefore be visible on gastroduodenoscopy. However, a bleeding leiomyoma is more likely to be beyond the range of upper gastrointestinal endoscopy. Nevertheless, an adequate negative examination is helpful, indicating a more distal source of haemorrhage. In cases 2 and 3 , the decision to perform angiography was based on normal appearances found at endoscopy.

The length of the small bowel and rapid transit of contrast through the intestine tend to reduce the effectiveness of barium studies. A radiological diag nosis of small bowel tumours is made in only a thir 9 to a half of symptomatic cases (River et al., 1956. Darling and Welch, 1959; Middleton, 1967; Wilson ex. al., 1975). Repeated barium follow-through examinż tions may appear normal, and occasionally eve laparotomy can be unrewarding (River et al., 1956b One patient reported by Menzies, Coutts and Edgê (1980) had intermittent melaena for 27 years, during which he had numerous investigations, including negative laparotomy, before the offending jejuna leiomyoma was finally identified at a second operas tion. In an even more extreme case, a patient had 280 episodes of melaena over 14 years. Several bariurz examinations and a laparotomy were negative. The patient subsequently suffered a fatal haemorrhage and the lesion was found to be a leiomyoma in the jejunum at autopsy (Hanno and Mensch, 1944).

More recently, angiography has been advocated iB demonstrating small bowel leiomyoma (Boijsen an $\bar{\phi}$ 
Reuter, 1966; Kanter, Schwartz and Fleming, 1968). Characteristic angiographic appearances include well circumscribed margins, prominent feeding arteries and draining veins, irregular tumour vessels giving rise to a dense stain and small pools of contrast within the mass (Ramer, Mitty and Baron, 1971). Although all these features need not be present in each case, the vascular pattern is quite constant. Using this technique, leiomyomata have been demonstrated in bleeding patients even when barium studies are negative (Burrows, Dodds, and Thompson, 1977; Forbes et al., 1978). In acute gastrointestinal haemorrhage, angiography is more likely to succeed if there is active bleeding exceeding 0.5 $\mathrm{ml} / \mathrm{min}$., and if contrast is injected into the appropriate feeding vessel (Gordan, Herlinger and Baum, 1981). In this series, early selective visceral angiography led to an accurate pre-operative diagnosis in the 2 more recent cases. The radiological findings were fairly typical of small bowel leiomyomata, and this undoubtedly helped surgical planning and reduced the duration of the operation.

Histologically, leiomyomata are well circumscribed, intramural tumours composed of whorls of smooth muscle. As they grow, the bowel lumen is compressed and stretching of the mucosa takes place, even through the bulk of the tumour may be on the serosal side. When bleeding occurs, it is usually associated with mucosal ulceration or cavitation. One or the other of these features was observed in all 3 cases, a common finding shared by others (Forbes $e t$ al., 1978; Christou, Stein and Meakins, 1979).

Haemorrhage from small bowel leiomyomata is frequently massive, and life threatening. A definitive diagnosis is often difficult, and tumours may be missed even at laparotomy. However, prognosis is excellent if the bleeding source can be identified and resected. For these reasons, an accurate pre-operative diagnosis is highly desirable. Experience from the medical literature and our small series appears to show that selective visceral angiography is a useful technique in localizing such tumours. This procedure should be seriously considered in severe or recurrent gastrointestinal haemorrhage if upper gastrointestinal endoscopy is negative.

\section{Acknowledgments}

We thank the surgeons and physicians of the Whittington and University College Hospitals for their kind permission to report cases under their care. We are particularly grateful to Mr Paul Savage, Dr E. Beck, Dr R. Vicary, Professor J. Wyllie and Mr M. R. Lock for their help and encouragement, and also to Mrs R. Motyer for preparing the manuscript.

\section{References}

BOIJSEN, E. \& REUTER, S.R. (1966) Mesenteric angiography in the evaluation of inflammatory and neoplastic disease of the intestine. Radiology. 87, 1028.

BurRows, F.G.O., DodDs, W.N. \& THOMPSON, H. (1977) Diagnosis of a leiomyoma of the small intestine by selective angiography. British Journal of Surgery, 64, 145.

Christou, N.V., Stein, L.A. \& Meakins, J.L. (1979) Recurrent gastrointestinal bleeding due to smooth muscle tumours of the small intestine. Canadian Journal of Surgery, 22, 95.

DARLING, R.C. \& WELCH, C.E. (1959) Tumours of the small intestine. New England Journal of Medicine, 260, 397.

Dronfield, M.W., Langman, M.J.S., AtKinson, M., Balfour, T.W.. Bell. G.D., VellacotT, K.D., AMAR, S.S. \& KNAPP, D.R. (1982) Outcome of endoscopy and barium radiography for acute upper gastrointestinal bleeding: controlled trial in 1037 patients. British Medical Journal, 284, 545.

Forbes, W. ST. C., Nolan, D.J., Fletcher, E.W.L. \& LeE, E. (1978) Small bowel melaena: 2 cases diagnosed by angiography. British Journal of Surgery, 65, 168.

Gordan, R., Herlinger, H. \& BaUm, S. (1981) Arteriography and Scintiscanning In: Gastrointestinal Haemorrhage, (eds. P. W. Dykes and M. R. B. Keighley), Ist edn., p. 209. Wright, PSG. Bristol.

GRILL, W. \& PiChlmaier, H. (1963) Leitsymptom: Haematemesis-Melaena. Munchener medizinische Wochenschrift, 105, 385.

HANNO, H.A. \& MENSCH, M. (1944) Leiomyoma of the jejunum. Intermittent melaena of 14 years' duration and fatal haemorrhage. Annals of Surgery, 120, 199.

KANTER, I.E., SCHWARTZ, A.J. \& FLEMING, R.J. (1968) Localization of bleeding point in chronic and acute gastrointestinal haemorrhage by means of selective visceral arteriography. American Journal of Roentgeneology, Radiation Therapy and Nuclear Medicine, 19, 126.

MENZIES. K.E., CoutTS. J.P. \& EDGE, D.P. (1980) Three cases of smooth muscle tumours of the small intestine. New Zealand Medical Journal, $91,422$.

MIDDLETON, W.R.J. (1967) Small bowel tumours. Australian Annals of Medicine, 16, 155.

RAMER, M., MitTy, H.A. \& Baron, M.G. (1971) Angiography in leiomyomatous neoplasms of the small bowel. American Journal of Roentgenology, 113, 263.

River, L., Silverstein, J. \& TOPE, J.W. (1956) Benign neoplasms of the small intestine. International Abstracts of Surgery, 102, 1.

Wilson, J.M., Melvin, D.B., Gray, G. \& ThORBJarnason, B. (1975) Benign small bowel tumour. Annals of Surgery, 181, 247.

(Accepted 18 June 1982) 